\title{
Discordance between Transferrin Receptor Expression and Susceptibility to Lysis by Natural Killer Cells
}

\author{
Kenneth R. Bridges and Brian R. Smith \\ Laboratory of Howard Hughes Medical Institute, Division of Hematology, Brigham and Women's Hospital; Division of Pediatric \\ Oncology, Dana Farber Cancer Institute; and Departments of Medicine and Pediatrics, Harvard Medical School, Boston, Massachusetts \\ 02115
}

\begin{abstract}
Expression of the transferrin receptor on target cell lines has recently been implicated as a determinant of susceptibility to cytolysis by natural killer (NK) lymphocytes. We have examined this proposed relationship in several ways. First, K562 (a cell line highly vulnerable to NK lysis) cells were grown for $24 \mathrm{~h}$ in the iron chelator desferrioxamine. Under these conditions, the cells doubled their surface transferrin receptor expression as determined both by radioligand binding and surface binding of the OK-T9 monoclonal anti-transferrin receptor antibody. In contrast, cells grown for the same period of time in hemin halved their receptor expression. This fourfold change in transferrin receptor expression between the desferrioxamine-treated and hemin-treated cells produced no change in susceptibility to NK cytolysis. Second, HeLa (a cell line which in its native state is very resistant to NK cytolysis) cells were compared with $\mathrm{K562}$ cells with respect to surface transferrin receptor expression. The difference in NK susceptibility of the two cell lines was not reflected in differences in transferrin receptor expression: the $\mathbf{K 5 6 2}$ cells expressed $\sim 1.5 \times 10^{5}$ receptors per cell while HeLa cells expressed $2.0 \times 10^{5}$ receptors/cell. Third, infection of HeLa cells by measles virus greatly increased their susceptibility to NK lysis but produced no change in surface transferrin receptor expression. Furthermore, when measles-infected HeLa cells were grown for $6 \mathrm{~d}$ in medium supplemented with iron-saturated human transferrin they underwent a 50\% reduction in receptor expression but no change in NK susceptibility. Finally, possible alterations in the surface expression of NK target antigens on modified cells were further assayed by their ability to serve as cold-target inhibitors of cytolysis of NK-sensitive target cells. We examined two groups of cells in which transferrin receptor expression was reduced. These were the transferrin-treated, measles-infected HeLa cells with the $50 \%$ receptor reduction, and $\mathrm{K} 562$ cells grown in medium containing hemin and iron salts where the reduction was five- to sixfold relative to control. In neither case was there a change in the apparent expression of NK target antigen(s).

We conclude that there is a discordance between transferrin receptor expression and susceptibility to NK cytolysis in the model systems examined. Therefore, it is unlikely that the transferrin receptor per se is the target recognition structure for human NK cells, although a role in concert with other, as yet undefined molecules, cannot be excluded.
\end{abstract}

Received for publication 20 September 1984 and in revised form 15 March 1985.

J. Clin. Invest.

(C) The American Society for Clinical Investigation, Inc.

0021-9738/85/09/0913/06 \$1.00

Volume 76, September 1985, 913-918

\section{Introduction}

Natural killer (NK) ${ }^{1}$ cells are a population of lymphocytes defined by their ability to kill certain virus-infected cells and tumor cells without prior antigen exposure $(1,2)$. Although the exact function of NK cells is not certain, speculation centers on a possible role in immune surveillance of transformed or tumor cells $(3,4)$. The target antigen(s) for the NK cell is unknown. Several studies, however, suggest that the transferrin receptor is the recognition site for NK cells $(5,6,7,8)$. This receptor serves as the physiological mode of cellular iron uptake by binding iron-laden transferrin (9). Iron is an essential element in metabolism, as a component of heme in enzymes such as peroxidases and cytochromes, and also as a component of nonheme, ironcontaining proteins. Proliferating cells have increased numbers of transferrin receptors when compared with cells in resting phase $(10,11)$, which presumably reflects the increased iron requirement of growing cells. That the transferrin receptor might be the target in proliferating tumor cells recognized by NK cells is then, at least, plausible. This interaction would allow the NK cells to destroy tumor cells at an early stage in their growth and thereby retard the development of malignancy.

Recently developed techniques allow a modulation of the expression of transferrin receptors in cells in tissue culture. HeLa cells grown in iron-supplemented medium or in medium containing human transferrin undergo a reduction in transferrin receptor expression, as do K562 cells grown in hemin $(12,13)$. In contrast, $\mathrm{K} 562$ cells grown in the presence of the iron chelator desferrioxamine show a marked increase in transferrin receptor expression $(14,15)$. This ability to modulate transferrin receptor expression in a single cell type provided an opportunity to test for a correlation between receptor expression and susceptibility to lysis by NK cells, particularly since the K562 line has been widely used as a target for NK studies (1). In addition, comparisons could be made of the transferrin receptor expression in NK-sensitive K562 cells, in NK-resistant HeLa cells, and in HeLa cells modified by measles virus infection, which are thereafter rendered NK-sensitive (2).

\section{Methods}

Cells. $\mathrm{K} 562$ cells were grown at $37^{\circ} \mathrm{C}$ in a $5 \% \mathrm{CO}_{2}$ atmosphere in RPMI 1640 medium (M.A. Bioproducts, Walkersville, MD) supplemented with L-glutamine and $10 \%$ fetal bovine serum (FBS; Gibco Laboratories, Grand Island, NY). The cells were maintained in a log-phase growth at a concentration of $5 \times 10^{5}$ cells $/ \mathrm{ml}$ by daily dilutions with an equal volume of medium. HeLa cells were maintained in the same medium and were kept at subconfluent levels. Monolayer HeLa cells were converted to suspensions by removing the growth medium and exposing the cells for $15 \mathrm{~min}$ at room temperature to $10 \mathrm{mM}$ EDTA in phosphate-buffered saline (PBS). After the HeLa cells were loosened from the plates, they

1. Abbreviations used in this paper: NK, natural killer. 
were returned to the RPMI/FBS medium for assay of surface transferrin receptors or susceptibility to NK cell lysis (see below).

Transferrin saturation and radiolabeling. Apotransferrin (Calbiochem-Behring Corp., La Jolla, CA) was saturated with iron as previously described using nitrilotriacetate and ferric chloride (Sigma Chemical Co. St. Louis, MO) (16). The diferric transferrin was separated from unincorporated iron on a PD-10 column (Pharmacia Fine Chemicals, Piscataway, $\mathrm{NJ}$ ). A ratio of A $465 \mathrm{~nm} / \mathrm{A} 280 \mathrm{~nm}$ of 0.045 indicated full saturation, and preparations with a ratio of $<0.040$ were discarded. Diferric transferrin was labeled with ${ }^{125}$ I using lodogen beads (Pierce Chemical Co., Rockford, IL) as previously described (14). The specific activities ranged from 5,000 to $15,000 \mathrm{cpm} / \mathrm{pmol}$ of protein.

Transferrin binding studies. Cell surface transferrin binding studies were performed as previously described (17). In brief, cells suspended at a concentration of $10^{7} / \mathrm{ml}$ in RMPI 1640 medium containing $1 \%$ FBS were chilled to $4^{\circ} \mathrm{C}$ at which time ${ }^{125} \mathrm{I}$-diferric transferrin was added to a final concentration of $100 \mathrm{nM}$. After a 20-min incubation, the cells were pelleted through an oil cushion of dibutyl phthalate/mineral oil (9: 1 ratio) and the tube tips containing the cell pellets and the cell surfacebound ${ }^{125}$ I-transferrin were severed and counted using a gamma counter (8000; Beckman Instruments, Inc., Fullerton, CA). Nonspecific binding was determined with a parallel set of tubes to which unlabeled diferric transferrin was added to a concentration of $10 \mu \mathrm{M} 15 \mathrm{~min}$ before adding ${ }^{125} \mathrm{I}$-diferric transferrin. The upper aqueous phase containing free ${ }^{125} \mathrm{I}$ diferric transferrin was also counted in some cases.

OK-T9 antibody surface binding studies. Anti-transferrin receptor OK-T9 monoclonal antibody (Ortho, Raritan, NJ) was resuspended in $1 \mathrm{ml}$ of physiological saline. $\sim 2 \times 10^{6}$ cells were pelleted at $200 \mathrm{~g}$ in 12 $\times 75 \mathrm{~mm}$ polystyrene tubes in an RC-2B refrigerated centrifuge (Beckman Instruments, Inc.) and were placed on ice after the removal of the supernatant. The OK-T9 antibody was diluted 1:5 and $50 \mu \mathrm{l}$ of cold antibody solution was added to the cells with vortexing and a 30-min incubation on ice. The cells were washed three times, each with $1 \mathrm{ml}$ of ice-cold PBS. The solution was decanted after the last wash and $100 \mu \mathrm{l}$ of fluorescein-isothiocyanate-conjugated goat anti-mouse antibody (BectonDickinson \& Co., Oxnard, CA) was added with vortexing and a second 30-min incubation on ice. The cells were washed twice with cold PBS, then fixed by adding $0.5 \mathrm{ml}$ of PBS and $0.5 \mathrm{ml}$ of $2 \%$ paraformaldehyde. The cells were vortexed and stored at $4^{\circ} \mathrm{C}$ until the fluorescence pattern could be analyzed with the flow cytometer (FACS Analyzer, BectonDickinson \& Co.). The amounts of OK-T9 antibody and fluorescent goat anti-mouse antibody used were titered and found to be saturating for their respective antigens.

Assays for susceptibility to NK cytolysis. Human blood cells were collected in preservative-free, heparinized tubes from normal donors. Monocyte-depleted mononuclear cells were prepared by incubation of the whole blood with carbonyl iron (Lymphocyte Separator Reagent; Technicon Instruments Corp., Tarrytown, NY) at $37^{\circ} \mathrm{C}$ for $1 \mathrm{~h}$ followed by layering on a Ficoll-Hypaque cushion, centrifugation for $40 \mathrm{~min}$ at $1,200 \mathrm{rpm}$, and removal of the mononuclear cells at the interface removed as previously described (18). These cells were used as effector lymphocytes. Target cells (HeLa, measles-infected HeLa, and K562) were chromated for $1 \mathrm{~h}$ at $37^{\circ} \mathrm{C}$ with ${ }^{51} \mathrm{Cr}$ (New England Nuclear, Boston, MA) at a concentration of $0.1 \mathrm{mCi} / 10^{6}$ cells and washed four times before use.

Target cells were plated in round-bottom microwell tissue culture plates (Flow Laboratories, McLean, VA) at a concentration of $2.5 \times 10^{4}$ cells/well. Effector lymphocytes were added at effector-to-target ratios of 1:1, 2.5:1, 5:1, 10:1, and 20:1 in triplicate wells for each cell line; the volume was adjusted to $200 \mu \mathrm{l}$ by adding supplemented RPMI 1640 medium; and the plates were incubated for 6 or $24 \mathrm{~h}$ at $37^{\circ} \mathrm{C}$. Background and $100 \%$ chromium release were determined by respective incubation of target cells either with medium alone or with $1 \%$ Triton X-100 (IGEPAL CA-630; GAF Corp, New York, NY) detergent. Supernatants were harvested using a supernatant collection system (Titer-tek; Flow Laboratories, McLean, VA) and chromium release was counted with a spectrometer (Biogamma II; Beckman Instruments, Inc.). Chromate release into the supernatant was a measure of target cell lysis. Percent cytolysis was calculated according to the formula: (cpm - background

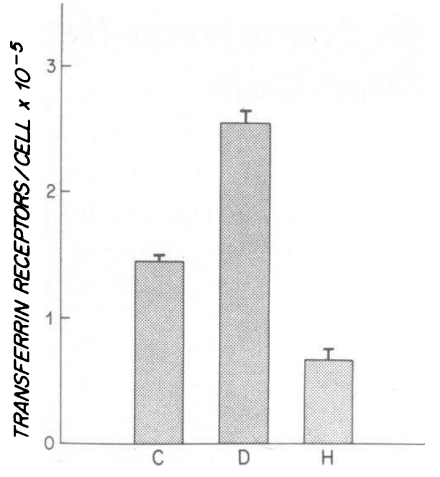

Figure 1. Cell surface transferrin receptor expression in control, desferrioxamine-treated, and hemin-treated K562 cells. Desferrioxamine and hemin were added to groups of cells, in triplicate, to final concentrations of 60 and $20 \mu \mathrm{M}$, respectively. A third group of cells served as controls. The cells were incubated for $24 \mathrm{~h}$ at $37^{\circ} \mathrm{C}$. They were then pelleted at $200 \mathrm{~g}$, the supernatant was removed, and the cells were resuspended in ice-cold RPMI 1640 medium containing 1\% FBS. The binding of ${ }^{125}$ l-diferric transferrin to surface receptors was performed as outlined in the text. The plotted values are the mean \pm SD.

$\mathrm{cpm}) /($ detergent $\mathrm{cpm}-$ background $\mathrm{cpm}) \times 100$. Spontaneous lysis in all experiments was $<5 \%$.

\section{Results}

K562 cell studies. K562 cells were grown for $24 \mathrm{~h}$ in control medium or in medium supplemented either with $60 \mu \mathrm{M}$ desferrioxamine or with $20 \mu \mathrm{M}$ hemin. These two agents had no effect on the rate of cell growth during this time, but markedly altered transferrin surface binding capacity (Fig. 1). There was a fourfold difference in transferrin receptor expression between the desferrioxamine and the hemin-treated cells. There were no morphological alterations in the cells.

The transferrin surface binding capacity is a functional measure of receptor number. It was possible, however, that NK cells might recognize functionally inactive transferrin receptors on the cell surface. The OK-T9 monoclonal antibody binds to the transferrin receptor at a site different than the transferrin-binding domain (19). This antibody was used to determine whether the hemin-induced and desferrioxamine-induced changes in functional receptor expression reflected changes in immunoreactive receptor on the cell surface.

Cells grown for $24 \mathrm{~h}$ in control medium and in desferrioxamine-supplemented or hemin-supplemented medium were chilled, washed, and labeled with a saturating concentration of OK-T9 antibody, followed by fluorescein-labeled goat antimouse antibody. Fig. 2 shows the results of such an analysis of desferrioxamine-treated and hemin-treated cells. Mean log fluorescence intensity in the hemin-treated cells was 90 (arbitrary) $\mathrm{U}$ vs. 133 in the desferrioxamine-treated cells. The logarithmic

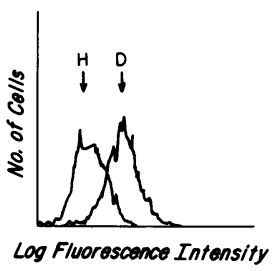

Figure 2. Cell surface transferrin receptor antigen in desferrioxamine-treated and hemintreated K562 cells. Cells were incubated with desferrioxamine or hemin for $24 \mathrm{~h}$ as described in the legend to Fig. 1. At that time the cells were labeled with monoclonal OKT9 anti-transferrin receptor antibody. Goat anti-mouse antibody conjugated with fluorescein isothiocyanate was then added to the cells and the fluorescence pattern was analyzed with the FACS. Increasing fluorescence intensity reflects increasing amounts of transferrin receptor antigen on the cell surface. " $D$ " indicates the fluorescence profile of the desferrixaminetreated cells, while " $\mathrm{H}$ " is the hemin-treated cells. 
amplifier in this experiment was set such that a change of $20 \mathrm{U}$ in the mean fluorescence corresponded to a twofold change in the absolute level of fluorescence. The 43-U difference between the hemin-treated and desferrioxamine-treated cells thus indicated a fourfold change in the mean level of antigenic receptor expression. This correlated well with the changes seen in functional receptor expression. Thus, the change in transferrin surface binding capacity seen in the treated cells reflected a change in the amount of receptor protein on the cell rather than an activation or inactivation of receptors.

Susceptibility to lysis by NK cells was determined for the various K562 cell groups by a chromium release assay. As described in Methods, target cells labeled with ${ }^{51} \mathrm{Cr}$ were incubated with enriched populations of human lymphocytes containing NK cells. In three separate experiments, the samples were assayed for chromium release as a measure of target cell lysis after 6 and $24 \mathrm{~h}$. Fig. 3 is a representative 6 -h killing assay showing that the K562 cells were highly susceptible to lysis under these conditions. An increase in transferrin receptor number by desferrioxamine or a decrease by hemin produced no change in NK cell susceptibility. All three experiments produced identical results. Given the fourfold difference in the level of receptor expression between the desferrioxamine-treated and hemin-treated cells, the data suggest that this receptor is not the sole determinant of NK cell susceptibility.

HeLa cell studies. HeLa cells are relatively resistant to lysis by NK cells except when altered by measles virus infection (2). When so infected, a two- to fourfold increased susceptibility to lysis by NK cells is observed. The levels of transferrin surface receptor expression were therefore compared in a HeLa control cell line and a measles-infected HeLa cell line (Fig. 4). The binding curves performed with increasing concentrations of ${ }^{125} \mathrm{l}$-diferric transferrin showed that both groups had $\sim 2 \times 10^{5}$ receptors per cell. The fact that the curves plateaued at the same transferrin concentrations indicated no significant difference existed in receptor affinity for transferrin. Attempts to increase transferrin receptor expression in HeLa cells by desferrioxamine treatment were unsuccessful as the cells failed to survive exposure to the chelator. Measles-infected HeLa cells grown in the presence of human transferrin showed a significant reduction in transferrin receptor expression to $\sim 1 \times 10^{5}$ receptors per cell (Fig. 4), similar to results previously noted for noninfected HeLa cells (12). The amount of transferrin-receptor antigen on the surfaces of these three groups of cells was also measured by OK-T9 antibody binding and FACS analysis. The mean values of $\log$ fluorescence intensity for the control and measles-infected HeLa cells were 127 and $123 \mathrm{U}$, respectively. The human transferrin-treated HeLa cells had a mean value of $101 \mathrm{U}$, indicating a 50\% reduction in transferrin receptor expression. As with the K562 cells,

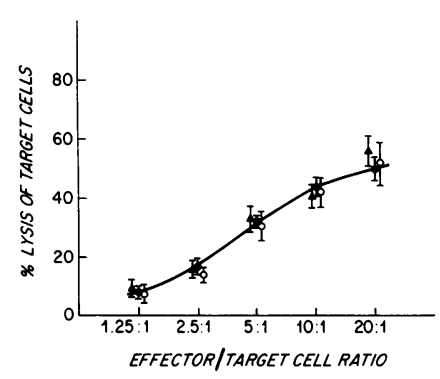

Figure 3. NK cell lysis of control (o), desferrioxaminetreated $(\bullet)$, and hemin-treated (ム) K562 cells. Cells were grown for $24 \mathrm{~h}$ in control, desferrioxamine-treated, or hemintreated medium as in Fig. 1. At that time they were assayed for susceptibility to lysis by NK cells at varying NK effector to $\mathrm{K} 562$ target cell ratios as described in the text.

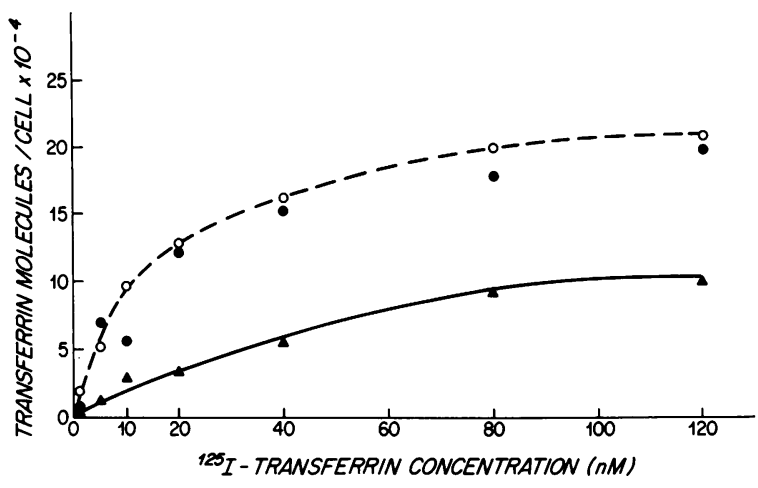

Figure 4. Transferrin surface binding profiles of HeLa cells, measlesinfected HeLa cells, and human transferrin-treated, measles-infected HeLa cells. Human diferric transferrin was added to subconfluent cultures of measles-infected HeLa cells to a final concentration of 7.5 $\mu \mathrm{M}$. The cells were incubated at $37^{\circ} \mathrm{C}$ for $6 \mathrm{~d}$, along with untreated measles-infected HeLa cells and uninfected HeLa cells. The culture media were changed every $2 \mathrm{~d}$. After $6 \mathrm{~d}$, all the cells were washed with RPMI 1640 medium with $10 \%$ FBS and were allowed to incubate for an additional $4 \mathrm{~h}$. The medium was then removed and the cells were detached from the plate with an EDTA/PBS solution. The cells were then resuspended at a concentration of $10^{7}$ cells $/ \mathrm{ml}$ in RPMI 1640/1\% FBS. 1/2-ml aliquots of the cells were incubated in ice with increasing concentrations of ${ }^{125} \mathrm{I}$-differic transferrin, and surface binding was determined as described in the text. (0), uninfected HeLa

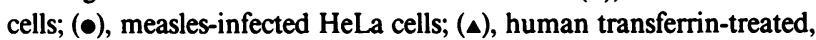
measles-infected HeLa cells.

the changes in the level of transferrin-receptor antigen correlated well with the changes in transferrin binding capacity.

HeLa cell infection by the virus drastically increases NK cell susceptibility as shown in Fig. $5 A$. And yet, the number of transferrin receptors expressed in HeLa cells and measles-infected HeLa cells was identical (Fig. 4). Viral infection produces substantial changes in the cell membrane, particularly with the expression of new surface glycoproteins. There was, however, no change in the expression of the transferrin receptor, either

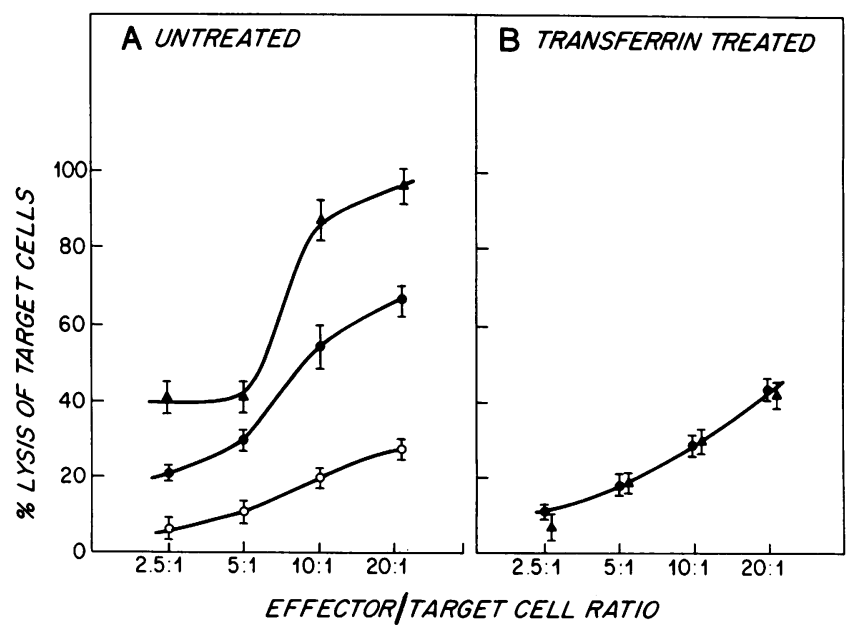

Figure 5. NK cell lysis of groups of HeLa cells. $(A)$ Lysis of uninfected HeLa cells ( $(0)$, measles-infected HeLa cells ( $\bullet$ ), and K562 cells ( () ) at varying NK effector cell-to-target cell ratios. The assays are described in the text. $(B)$ NK cell lysis of measles-infected HeLa cells $(\bullet)$ and of measles-infected HeLa cells exposed to human transferrin (४). 
functionally or immunologically. This is strong evidence that the transferrin receptor alone is not the target for the NK cell. As shown in Fig. 4, growth of measles-infected HeLa cells in medium containing human transferrin for $6 \mathrm{~d}$ reduced by half the level of transferrin receptor expression. This change, however, produced no alteration in the level of NK cell susceptibility, as shown in Fig. 5 B. The assay for target cell lysis was conducted after 6 and $24 \mathrm{~h}$ of incubation in medium containing no human transferrin. Under these conditions there could have been recovery of transferrin receptor expression in the transferrintreated, measles-infected HeLa cells. These cells were, therefore, assayed for transferrin surface binding capacity 6 and $24 \mathrm{~h}$ after the removal of the medium containing the human transferrin. At the 6-h assay point the cells had $40 \%$ of the control level of transferrin receptors, while at $24 \mathrm{~h}$ the value was still only $72 \%$ of control.

Cold-target inhibition studies. The correlation between transferrin receptor expression and NK susceptibility previously noted (5), indicated that this interdependency held only to a certain level of receptor expression. A strong positive correlation existed for cells with fewer receptors than K562, but beyond this NK susceptibility reached a plateau. Any test of this hypothesis would therefore require experiments in which changes in NK susceptibility were sought in response to decreases in the level of transferrin receptor expression to below that seen in K562 cells.

A series of experiments was performed wherein cells whose surface receptors had been down-regulated were used as competitive "cold-target inhibitors". Here the ratio of NK effector cells to labeled target cells is held constant while increasing numbers of a group of unlabeled second target cells were added. The ability of the unlabeled cells to prevent the lysis of the labeled target cells is thought to be a function of the quantity of the specific NK target antigen(s) on the unlabeled cells. Therefore, this may be a more sensitive way to examine NK target antigen expression, since it separates target recognition from cell lysis.

As shown earlier, HeLa, measles-infected HeLa, and K562 cells have roughly the same number of transferrin receptors. Measles-infected HeLa cells in which transferrin receptor expression was halved by prior growth with saturated human transferrin were used in cold-target inhibition studies along with unmodified, measles-infected cells. As shown in Table I, the two groups of cells were equally effective as cold-target inhibitors. The reduction in receptor expression to below the K562 "standard" in the transferrin-modified, measles-infected HeLa cells would have placed them in a range where covariance of transferrin receptor expression and NK susceptibility should have occurred. This was not seen.

Since it was possible that the level of receptor reduction in this experiment was still insufficient to make such a relationship apparent, a series of experiments was performed in which receptor-modulated and unmodified K562 cells were used as coldtarget inhibitors. To attain a greater degree of reduction of transferrin receptor expression, cells were grown for $5 \mathrm{~d}$ in medium supplemented with $10 \mu \mathrm{M}$ hemin and $5 \mu \mathrm{g} / \mathrm{ml}$ ferric ammonium citrate. The combined use of hemin and the iron salt produced a reduction in receptor expression from $1.72 \times 10^{5}$ to 0.33 $\times 10^{5}$ per cell in the first series of experiments (fivefold), and from $1.63 \times 10^{5}$ to $0.27 \times 10^{5}$ per cell (sixfold) in the second. As shown in Table II, for each experiment untreated K562 cells were used as "hot" targets in one inhibition series, while hemin/ iron treated cells were used as "hot" targets to another. Inhibition of lysis of untreated K562 target cells by treated and untreated cold targets was comparable down to a cold/hot target ratio of $4: 1$ in both experiments. The treated cells were less potent inhibitors at an 8:1 ratio. A two-tailed chi-square analysis of the inhibition series showed that there was no significant difference between the treated and untreated cells as cold-target inhibitors $(P<0.05)$. Similarly, when the treated K562 cells were used as "hot" targets, the cold-target inhibition by the treated and untreated cells was identical.

\section{Discussion}

The NK cell is a member of the immune system's armamentarium; its exact role is uncertain. One hypothesis is that NK cells provide an immune surveillance mechanism that can destroy tumor cells at an early stage of development $(3,4)$. Eradication of tumors is more difficult with large cell burdens, so that

Table I. "Cold-target Inhibition" of NK-mediated K562 Cytolysis by Unlabeled Measles-infected HeLa Cells

\begin{tabular}{|c|c|c|c|c|}
\hline \multirow[b]{2}{*}{$\begin{array}{l}\text { Ratio of unlabeled } \\
\text { “cold" target cells } \\
\text { to labeled K562 } \\
\text { target cells }\end{array}$} & \multicolumn{2}{|l|}{$E / T=10: 1$} & \multicolumn{2}{|l|}{$E / T=5: 1$} \\
\hline & $\begin{array}{l}\text { "Cold" target } \\
=\text { measles-infected HeLa cells }\end{array}$ & $\begin{array}{l}\text { "Cold" target } \\
=\text { transferrin-treated } \\
\text { measles-infected HeLa cells }\end{array}$ & $\begin{array}{l}\text { "Cold" target } \\
=\text { measles-infected HeLa cells }\end{array}$ & $\begin{array}{l}\text { "Cold" target } \\
\text { = transferrin-treated } \\
\text { measles-infected HeLa cells }\end{array}$ \\
\hline \multicolumn{5}{|l|}{ 6-h assay } \\
\hline $0.5: 1$ & $46.5 \pm 5.9$ & $45.2 \pm 2.8$ & $24.5 \pm 3.4$ & $25.1 \pm 3.1$ \\
\hline $1: 1$ & $36.8 \pm 4.0$ & $36.4 \pm 3.8$ & $18.1 \pm 1.8$ & $20.7 \pm 1.8$ \\
\hline $2: 1$ & $31.8 \pm 4.2$ & $34.4 \pm 4.3$ & $19.6 \pm 3.1$ & $22.0 \pm 2.1$ \\
\hline $4: 1$ & $24.9 \pm 3.4$ & $25.1 \pm 3.2$ & $14.4 \pm 2.2$ & $14.2 \pm 2.4$ \\
\hline $8: 1$ & $21.2 \pm 2.3$ & $23.0 \pm 2.6$ & $10.2 \pm 2.2$ & $12.5 \pm 1.7$ \\
\hline \multicolumn{5}{|l|}{ 24-h assay } \\
\hline $0.5: 1$ & $55.1 \pm 3.7$ & $54.8 \pm 5.8$ & $35.6 \pm 3.5$ & $29.4 \pm 7.9$ \\
\hline $1: 1$ & $60.9 \pm 7.9$ & $52.8 \pm 5.6$ & $27.9 \pm 2.3$ & $31.1 \pm 2.7$ \\
\hline $2: 1$ & $45.0 \pm 5.2$ & $45.2 \pm 5.0$ & $25.0 \pm 2.9$ & $25.7 \pm 2.5$ \\
\hline $4: 1$ & $35.3 \pm 3.1$ & $36.8 \pm 4.5$ & $17.5 \pm 2.7$ & $18.9 \pm 2.2$ \\
\hline $8: 1$ & $30.2 \pm 4.0$ & $29.1 \pm 3.3$ & $19.1 \pm 2.7$ & $21.0 \pm 2.1$ \\
\hline
\end{tabular}

As described in the text, increasing numbers of "cold" measles-infected HeLa cells (either unmodulated or cultured in transferrin) were added to 6- or 24-h cytolysis assays measuring the progressive inhibition of the lysis of labeled K562 cells (targets) by human blood NK cells (effectors). Assays were performed at effector/target ratios (E/T) of 10:1 and 5:1. 
Table II. NK-mediated Cytolysis of Native K562 Target Cells ("Untreated") Vs. K562 Target Cells Modified by Treatment with Hemin Plus Iron ("Treated"): "Cold-Target Inhibition"*

\begin{tabular}{|c|c|c|c|}
\hline \multirow[b]{2}{*}{$\begin{array}{l}\text { Killing of K562 } \\
\text { ("hot") target cells }\end{array}$} & \multirow[b]{2}{*}{$\begin{array}{l}\text { "Cold:hot" } \\
\text { target ratio } \\
\text { (unlabeled/labeled) }\end{array}$} & \multicolumn{2}{|c|}{$\begin{array}{l}\text { Unlabeled ("cold") } \\
\text { target inhibitor }\end{array}$} \\
\hline & & $\begin{array}{l}\text { Untreated } \\
\text { K562 }\end{array}$ & $\begin{array}{l}\text { Treated } \\
\text { K562 }\end{array}$ \\
\hline \multicolumn{4}{|l|}{ Experiment 1} \\
\hline \multirow[t]{6}{*}{ Untreated } & $0: 1$ & $49.7 \pm 5.9$ & \\
\hline & $0.5: 1$ & $36.4 \pm 4.5$ & $39.0 \pm 4.0$ \\
\hline & $1: 1$ & $23.9 \pm 3.2$ & $22.9 \pm 4.0$ \\
\hline & $2: 1$ & $25.9 \pm 3.2$ & $30.4 \pm 4.1$ \\
\hline & $4: 1$ & $19.8 \pm 2.6$ & $26.5 \pm 5.5$ \\
\hline & $8: 1$ & $11.6 \pm 2.4$ & $21.6 \pm 2.3$ \\
\hline \multirow[t]{6}{*}{ Hemin treated } & $0: 1$ & $39.8 \pm 2.0$ & \\
\hline & $0.5: 1$ & $35.2 \pm 5.0$ & $32.0 \pm 4.4$ \\
\hline & $1: 1$ & $18.0 \pm 5.2$ & $23.8 \pm 3.0$ \\
\hline & $2: 1$ & $30.0 \pm 3.4$ & $22.7 \pm 1.9$ \\
\hline & $4: 1$ & $22.9 \pm 5.2$ & $15.7 \pm 2.7$ \\
\hline & $8: 1$ & $18.0 \pm 3.7$ & $15.0 \pm 2.6$ \\
\hline \multicolumn{4}{|l|}{ Experiment 2} \\
\hline \multirow[t]{6}{*}{ Untreated } & $0: 1$ & $36.8 \pm 6.7$ & \\
\hline & $0.5: 1$ & $29.8 \pm 4.4$ & $36.4 \pm 0.5$ \\
\hline & $1: 1$ & $24.5 \pm 2.5$ & $22.4 \pm 4.0$ \\
\hline & $2: 1$ & $19.8 \pm 4.7$ & $21.8 \pm 4.9$ \\
\hline & $4: 1$ & $10.5 \pm 2.5$ & $18.1 \pm 4.2$ \\
\hline & $8: 1$ & $7.0 \pm 1.4$ & $16.3 \pm 2.7$ \\
\hline \multirow[t]{6}{*}{ Hemin treated } & $0: 1$ & $81.9 \pm 30.6$ & \\
\hline & $0.5: 1$ & $72.4 \pm 21.4$ & $78.5 \pm 26.5$ \\
\hline & $1: 1$ & $53.1 \pm 18.8$ & $47.7 \pm 16.5$ \\
\hline & $2: 1$ & $48.6 \pm 17.9$ & $35.2 \pm 13.9$ \\
\hline & $4: 1$ & $39.7 \pm 12.5$ & $46.4 \pm 14.5$ \\
\hline & $8: 1$ & $25.1 \pm 9.0$ & $26.0 \pm 9.2$ \\
\hline
\end{tabular}

* Effector/target ratio, 10:1.

a mechanism that destroyed such cells early in their growth would provide a valuable defense against neoplasia (20). NK cells may also provide a first-line host defense against viral infections (21, 22). This concept is supported by the fact that NK cytotoxicity is augmented by interferon, which is produced by virally infected cells (23). Recent data suggest that NK cells may, in addition, play a role in regulating hematopoiesis. Studies showing an in vitro inhibition of granulopoiesis and suppression of erythroid stem cell proliferation by NK cells support this concept (24, $25,26)$.

Despite extensive investigations, however, the structure of the NK target cells that mark them for cytolysis has yet to be definitively identified. Some recent studies have suggested that the transferrin receptor may be the target antigen for NK cell cytolysis $(5,6,7,8)$. Several cell lines were examined to discern the number of cells in their populations that expressed the transferrin receptor and the degree of NK susceptibility of the line. Those cell lines with few receptor-positive cells were resistant to NK cytolysis (5). However, in cell lines containing $>50 \%$ receptor-positive cells in their populations, there was a range of susceptibility to NK lysis from highly sensitive to insensitive. In addition, a purified trypsin-cleavage fragment of the transferrin receptor could partially block the cytolytic activity of the NK cells.
In another study, mouse L-cells were transfected with sheared human DNA, and cells that subsequently expressed the human transferrin receptor on their surface were selected for and cloned (8). These transformed mouse L-cells could partially inhibit cytolysis of labeled K562 target cells by human peripheral blood lymphocytes when used in a cold-target inhibition assay. This suggested that the human transferrin receptor played a role in the affector-target interaction, though, interestingly, nontransformed L-cells also produced significant inhibition. In contrast to the data in human systems, there was no correlation between mouse transferrin receptor expression and NK recognition in a murine system.

Since the transferrin receptor is the physiologic mode of iron acquisition by cells, the implications of these studies are farreaching. The receptor is expressed on proliferating cells such as tumor cells in culture, cultured fibroblasts, and erythroid precursors, as well as nonproliferating cells such as reticulocytes and hepatocytes $(10,11,27-30)$. If the transferrin receptor was the target structure for NK cells, these young reticulocytes would be in grave danger of destruction.

Here, the relationship between transferrin receptor expression and NK cytolysis was examined in several ways. The NK-sensitive K562 cell has been widely used as a standard target in NK studies. The transferrin receptor expression on the surface of these cells was increased by treatment with desferrioxamine or decreased by treatment with hemin. A fourfold difference in both functional and antigenic receptor expression was achieved between the desferrioxamine and the hemin-treated cells. Nonetheless, no difference in the extent of susceptibility to NK cytolysis was observed. A recent study in which transferrin receptor expression was reduced in K562 cells by several manipulations also failed to show a corresponding reduction in NK susceptibility (31).

The degree of difference in transferrin receptor expression in the desferrioxamine and hemin-treated cells was similar to that between the cell lines with different NK susceptibility reported previously (5). These data, then, suggest that the transferrin receptor is not the target antigen for NK cells. The possibility remained, however, that the degree of modulation of receptor expression was insufficient to cause a change in NK susceptibility in the K562 cells.

The HeLa cell line, which was resistant to NK cytolysis, was examined to determine whether an increased resistance correlated with the presence of fewer transferrin receptors than were seen in K562 cells. The HeLa cells were found to have slightly more transferrin receptors than the K562 cells. Measles infection of HeLa cells caused this cell line to become sensitive to lysis by human NK cells (2). This increased sensitivity to NK cytolysis, however, was not reflective of an increase in transferrin receptor expression. Control and measles-infected HeLa cells have the same number of functional and antigenic transferrin receptors.

Since it was previously reported that a strong correlation between the level of transferrin receptor expression and NK susceptibility existed only with lines having fewer receptors than K562 (5), it was important to determine whether shifts of receptor expression in this range produced a covariance in NK susceptibility. The cold-target inhibition method was used to examine NK target antigen expression on the cells.

Measles-infected HeLa cells grown for $6 \mathrm{~d}$ in medium-supplemented human transferrin showed a 50\% reduction in transferrin receptor expression, both functionally and antigenically, with no change in NK target antigen expression (Table I). Since the base-line transferrin receptor expression in K562 and mea- 
sles-infected HeLa cells is comparable, the transferrin-treated, measles-infected HeLa cells would have fallen in a range where a positive correlation between receptor expression and NK susceptibility would have been expected. The K 562 cells, incubated for $5 \mathrm{~d}$ in medium supplemented with hemin and iron salts, underwent a five- to sixfold reduction in the level of transferrin expression. These cells would have fallen well within the range where a linear correlation between receptor expression and NK susceptibility was reported (5). Despite this marked reduction in receptor expression, there was no evidence of a change in level of NK target antigen as determined by cold-target inhibition (Table II). When untreated K562 cells were used as targets, the hemin/iron treated cells were less effective as cold target inhibitors at the highest cold/hot target ratio. When the inhibition curves were statistically analyzed as a whole, however, the two groups of cells were not different. In the obverse experimental series where hemin/iron treated cells were used as hot targets, there was clearly no difference in the capacity of treated and untreated K562 cells to serve as cold-target inhibitors. The expression of NK target antigen on these two groups of cells, then, appeared to be equal.

NK cell targeting is, doubtless, a complex affair and many parameters may be involved. The factors controlling the targeting of virally infected cells may differ from those involved in tumor cell recognition. In addition, NK cells may be a heterogeneous population grouped together by their functional definition. Recently, a monoclonal antibody was used to isolate a subset of NK cells that was cytotoxic for an anchorage-dependent cell line but not for K562 cells (32). It is likely that this subset of NK cells recognizes a target antigen other than the transferrin receptor since the K562 cells express this receptor in abundance. In aggregate, these data show minimal, if any, correlation between transferrin receptor expression and susceptibility to NK lysis over a wide range of receptor expression. This strongly implies that the transferrin receptor is not the sole target structure for NK cell recognition.

\section{References}

1. Ortaldo, J. R., and R. B. Herberman. 1984. Heterogeneity of natural killer cells. Annu. Rev. Immunol. 2:359-394.

2. Ault, K. A., and H. L. Weiner. 1979. Natural killing of measlesinfected cells by human lymphocytes. J. Immunol. 122:2611-2616.

3. Herberman, R. B., editor. 1980. Natural Cell Mediated Immunity Against Tumors. Academic Press, Inc., New York. 1321 pp.

4. Dennert, G. 1980. Cloned lines of natural killer cells. Nature (Lond.). 287:47-49.

5. Vodinelich, L., R. Sutherland, C. Schneider, R. Newman, and M. Greaves. 1983. Receptors for transferrin may be a "target" structure for natural killer cells. Proc. Natl. Acad. Sci. USA. 80:835-839.

6. Baines, M. G., F. L. Lafleur, and B. E. Holbein. 1983. Involvement of transferrin receptors in human natural killer effector:target interactions. Immunol. Lett. 7:51-55.

7. Alarcon, B., and M. Fresno. 1985. Specific effect of anti-transferrin antibodies on natural killer cells directed against tumor cells: evidence for the transferrin receptor being one of the target structures recognized by NK cells. J. Immunol. 134:1286-1291.

8. Newman, R. A., J. F. Warner, and G. Dennert. 1984. NK recognition of target structures: is the transferrin receptor the NK target structure? J. Immunol. 133:1841-1845.

9. Aisen, P., and I. Listowsky. 1980. Iron transport and storage proteins. Annu. Rev. Biochem. 49:357-393.

10. Larrick, J. W., and P. Cresswell. 1979. Modulation of cell surface iron transferrin receptors by cellular density and state of activation. $J$. Supramol. Struct. 11:579-586.
11. Frazier, J. C., J. H. Caskey, M. Yoffee, and P. A. Seligman. 1982. Studies of the transferrin receptor on both human reticulocytes and nucleated human cells in culture. J. Clin. Invest. 69:853-865.

12. Ward, J. H., J. P. Kushner, and J. Kaplan. 1982. Regulation of Hela Cell Transferrin Receptors. J. Biol. Chem. 257:10317-10323.

13. Pelicci, P. G., A. Tabilio, P. Thomopoulos, M. Titeux, W. Vainchenker, H. Ronchant, and U. Testa. 1982. Hemin regulates the expression of transferrin receptors in human hematopoietic cell lines. FEBS (Fed. Eur. Biochem. Soc.). Lett. 145:350-354.

14. Bridges, K. R., and A. Cudkowicz. 1984. Effect of iron chelators on the transferrin receptor in K562 cells. J. Biol. Chem. 259:1297012977.

15. Mattia, E., R. Krishnamurty, D. S. Shapiro, H. H. Sussman, and R. D. Klausner. 1984. Biosynthetic regulation of the human transferrin receptor by desferrioxamine in K562 cells. J. Biol. Chem. 259:26892692.

16. Zaman, Z., M.-J. Heynen, and R. L. Verwilghen. 1980. Studies on the mechanism of transferrin iron uptake by rat reticulocytes. Biochim. Biophys. Acta. 632:553-561.

17. Klausner, R. D., J. Van Renswonde, G. Ashwell, C. Kempf, A. N. Schechter, A. Dean, and K. R. Bridges. 1983. Receptor-mediated endocytosis of transferrin in K562 cells. J. Biol. Chem. 258:4715-4724.

18. Timonen, T., C. W. Reynolds, J. R. Ortaldo, and R. B. Herberman. 1982. Isolation of human and rat natural killer cells. J. Immunol. Methods. 51:269-274.

19. Sutherland, R., D. Delia, C. Schneider, R. Newman, J. Kemshead, and M. Greaves. 1981. Ubiquitous cell-surface glycoprotein on tumor cells is proliferation-associated receptor for transferrin. Proc. Natl. Acad. Sci. USA. 78:4515-4519.

20. Durie, B. G., S. E. Salmon, and T. E. Moon. 1980. Pretreatment tumor mass, cell kinetics, and prognosis in multiple myeloma. Blood. 55:364-372.

21. Herberman, R. B., and J. R. Ortaldo. 1981. Natural killer cells: their role in defenses against disease. Science (Wash. DC). 214:24-30.

22. Bancroft, G. J., G. R. Shellam, and J. E. Chalmer. 1981. Genetic influences on the augmentation of natural killer cells during murine cytomegalovirus infection: correlation with patterns of resistance. J. Immunol. 126:988-994.

23. Einhorn, S., H. Blomgren, and B. Strander. 1978. Interferon and spontaneous cytotoxicity in man. 1. Enhancement of the spontaneous cytotoxicity of peripheral lymphocytes by human leucocyte interferon. Int. J. Cancer. 22:405-410.

24. Hansson, M., M. Beran, B. Andersson, and R. Kiessling. 1982. Inhibition of in vitro granulopoiesis by autologous allogeneic human natural killer cells. J. Immunol. 129:126-132.

25. Mangon, K. F., M. E. Hartnett, S. A. Matis, A. Winkelstein, and T. Abo. 1984. Natural killer cells suppress human erythroid stem cell proliferation in vitro. Blood. 63:260-269.

26. Holmberg, L. A., B. A. Miller, and K. A. Ault. 1984. The effect of natural killer cells on the development of syngeneic hematopoietic progenitors. J. Immunol. 133:2933-2939.

27. Iacopetta, B. J., E. G. Morgan, and G. C. T. Yeoh. 1982. Transferrin receptors and iron uptake during erythroid cell development. Biochim. Biophys. Acta. 687:204-210.

28. Young, S. P., and P. Aisen. 1981. Transferrin receptors and the uptake and release of iron by isolated hepatocytes. Hepatology (Baltimore). 1:114-119.

29. Nunez, M.-T., and J. Glass. 1983. The transferrin cycle and iron uptake in rabbit reticulocytes. J. Biol. Chem. 258:9676-9680.

30. Iacopetta, B. J., and E. H. Morgan. 1983. The kinetics of transferrin endocytosis and iron uptake from transferrin in rabbit reticulocytes. J. Biol. Chem. 258:9108-9115.

31. Dokhelar, M.-C., D. Garson, U. Testa, and T. Tursz. 1984. Target structure for natural killer cells: evidence against a unique role for transferrin receptor. Eur. J. Immunol. 14:340-344.

32. Rola-Pleszcznyski, M., and H. Lien. 1983. Human natural cytotoxic lymphocytes: definition by a monoclonal antibody of a subset which kills an anchorage-dependent target cell line but not the K562 cell line. Cell Immunol. 82:326-333. 